\title{
ORALIDAD E IMAGEN EN EL DISCURSO PUBLICITARIO DE LAS REDES SOCIALES
}

\author{
Eladio DUQUE \\ Universidad Complutense de Madrid (España)
}

\begin{abstract}
RESUMEN
Este artículo estudia dos características fundamentales del discurso publicitario en las redes sociales: los rasgos de la oralidad conceptual en el modo verbal y su integración multimodal con la imagen digital. Para ello, propone un análisis de corpus del caso de éxito de la cuenta de Twitter de Netflix España. Los resultados muestran que la oralidad conceptual se construye a partir de tres parámetros principales: la dialoguicidad, la implicación emocional y la familiaridad. Estos parámetros se manifiestan tanto en rasgos morfosintácticos y léxicos como en estrategias discursivas basadas en el humor y en el anclaje de las implicaturas conversacionales en asuntos de actualidad. La imagen presenta una función limitada en el fomento de la interacción o dialoguicidad; en cambio, desempeña un papel muy destacado en la comunicación de emociones y en la consecución de los efectos humorísticos.
\end{abstract}

PALABRAS CLAVE: continuo oralidad-escritura; multimodalidad; comunicación online; discurso digital.

\section{ABSTRACT}

This article deals with two key features of advertising discourse on social media: conceptual orality in the verbal mode and its multimodal integration with digital image. To this end, we conduct a corpus analysis of the successful case of the Twitter account of Netflix España. Results show that conceptual orality is built on the basis of three main parameters: dialogicity, emotional involvement and familiarity. These parameters are realized by means of lexico-grammatical features together with discursive strategies grounded in humour and in conversational implicatures related to current affairs. Image has a limited impact in boosting interaction or dialogicity; however, it plays a vital function in the expression of emotions and humour.

KEYWORDS: spoken-written continuum; multimodality; online communication; digital discourse. 


\section{INTRODUCCIÓN}

Hace tiempo que la oposición entre oralidad y escritura se entiende de manera más precisa como un espacio continuo matizado por diferentes dimensiones, parámetros contextuales o condicionantes (Biber et al. 2006; Conrad y Biber 2013; Briz 2010; Cortés y Camacho 2003; Koch y Oesterreicher 2007; González Ruiz y Martínez Pasamar 2002; López Serena 2021; Parodi 2005, entre otros). En el polo oral conceptual o de inmediatez comunicativa coinciden, entre otros parámetros, la espontaneidad, la copresencia de los interlocutores, el carácter dialógico, la implicación emocional y la confianza o familiaridad; en el polo escrito o de distancia comunicativa concurren la planificación, la distancia física, el carácter monológico, la baja implicación emocional y el desconocimiento de los interlocutores, entre otras condiciones comunicativas (Koch y Oesterreicher 2007: 26 y ss.).

Según el modelo de análisis del discurso oral propuesto por Cortés (2012), los parámetros anteriores definen la variación externa del discurso y se revelan en los textos mediante los rasgos lingüísticos concretos que definen la variación interna: mecanismos, estrategias de verbalización y realizaciones textuales que producen efectos discursivos. De este modo, por ejemplo, la participación emocional alta se manifiesta en la mayor frecuencia de adjetivos valorativos y de estructuras enfáticas; la copresencia de los interlocutores, en los deícticos y en el apoyo del lenguaje no verbal; la dialoguicidad, en la mayor presencia de enunciados interrogativos y en las fórmulas para gestionar los turnos; el conocimiento mutuo, en las frecuentes elipsis e implicaturas, etc. Lo habitual es encontrarnos con textos en los que estos parámetros se dan en diferente medida y que, por tanto, presentan rasgos asociados a la oralidad y a la escritura conceptual, esto es, a la inmediatez y distancia comunicativa.

La lengua utilizada en los chats y en las redes sociales se sitúa en un lugar cercano al extremo oral del continuo, dado que se caracteriza por «la inmediatez, una fuerte personalización y una predisposición constante a dialogar, gracias a 'tecnologías fáticas' que refuerzan los lazos sociales» (Mancera y Pano 2013a: 8). Por su parte, la lengua de la publicidad, con frecuencia, también se sitúa cerca del extremo oral, en su caso, como forma de apelación (Robles 2004) o como estrategia de acercamiento al destinatario (Hernández Toribio 2006: 71 y ss.), mediante «el triunfo de lo cotidiano» (íb. 183 y ss.) y de lo emocional (Hernández Toribio y Mariottini 2020). De este modo, tanto los parámetros contextuales que definen la comunicación en las redes sociales como los que definen los textos publicitarios predicen la importancia de la oralidad conceptual en las prácticas comunicativas de la publicidad en las redes sociales. El estudio de cómo estos parámetros de la variación externa se materializan en rasgos concretos de la variación interna del discurso es el primer objetivo de este artículo. 
El discurso publicitario y la comunicación en las redes sociales comparten otra propiedad fundamental: el importante papel que desempeña la imagen en la configuración de sus textos y el alto nivel de integración de la imagen con el modo verbal (Cantamutto y Vela Delfa 2016; Duque 2020a; Helfrich 2018; Gallardo-Paúls et al. 2018; Garrido 2008, entre otros). La palabra y la imagen no son modos inconmensurables y el análisis de textos multimodales puede abordarse a partir de categorías comunes entre los dos modos y de las maneras en las que dichos modos se combinan para lograr un propósito comunicativo común (Bateman 2014a: 7). El análisis de la contribución de la imagen a la expresión de cercanía o distancia comunicativa en la publicidad en las redes y el estudio de las relaciones de integración entre texto e imagen es el segundo objetivo de este artículo.

Para llevar a cabo estos dos objetivos, proponemos un estudio de corpus del caso de éxito de la cuenta corporativa más seguida en Twitter España ${ }^{1}$ : la plataforma de vídeos bajo demanda Netflix, @ NetflixES, que cuenta con más de un millón de seguidores.

\section{MARCO TEÓRICO}

\subsection{Oralidad en el discurso de las redes sociales}

La lengua utilizada en los chats, mensajes instantáneos y en las redes sociales suele vincularse a la oralidad y a la cercanía comunicativa, hasta el punto de que sus textos han sido calificados como «escritos oralizados», en los que predomina un estilo conversacional, interactivo y coloquial, de intervenciones breves y gran participación emocional (Yus 2011: 174 y ss.). Con todo, esta cercanía a la oralidad conceptual debe entenderse, también en los contextos de interacción digital, como un fenómeno variable y escalar (Bös y Kleinke 2017; Herring 2007 y Overbeck 2017) que puede describirse a partir de los parámetros contextuales de estudio del continuo inmediatez-distancia comunicativa (Koch y Oesterreicher 2007).

Entre los factores situacionales de la comunicación en Twitter que son relevantes para su ubicación en el continuo oralidad-escritura destacan, en el extremo oral o de cercanía, su acentuado carácter dialogal (Pano y Mancera 2014) y en el extremo escrito o de distancia, el carácter público de sus mensajes y el hecho de que sus usuarios no mantengan relaciones de reciprocidad y no se conozcan entre sí (Mancera y Pano 2013b). Esta particularidad de Twitter ha llevado a cuestionar que sea una red social propiamente dicha, ya que su finalidad se vincula más con la información y la

1 Según datos de <https://es.statista.com> de abril de 2020. 
expresión de la opinión que con el énfasis de «la sociabilidad, el contacto y la intimidad continuados» propio de otras redes sociales (Mancera y Pano 2013b: 58).

En cuanto a la variación interna, aunque, como se ha indicado, Twitter «presenta parámetros que lo acercan a la lengua de la distancia [...], la lengua de sus mensajes está más cerca del extremo de la inmediatez» (García Aguiar 2019: 210-211) y muestra los rasgos típicos de la interacción cara a cara entre amigos (Landert 2017: 43). Estos rasgos incluyen «el empleo del imperativo» o "enunciados interrogativos que, en segunda persona, buscan el comentario de los lectores» (García Aguiar 2019: 225); el léxico cargado emocionalmente, expresiones que remiten explícitamente al hablante y oyente, expresiones de énfasis como exclamaciones, el uso de mayúsculas y emoticonos (Landert 2017: 32) y una abundante presencia del humor (Chiaro 2017; Pano y Mancera 2016, o Vásquez 2019, entre otros).

A pesar de las características generales expuestas, como se ha indicado, es problemático considerar la comunicación en las redes sociales -incluso en una misma red social- como formas textuales claramente delimitables, ya que en ellas se agrupan prácticas comunicativas muy diversas, que incluyen desde las comunicaciones horizontales entre usuarios que comparten mismos intereses, hasta las comunicaciones verticales propias del discurso publicitario en las redes sociales, cuya diferente configuración del contexto situacional podría resultar en diferentes rasgos de la variación interna del discurso.

\subsection{Oralidad en el discurso publicitario}

Muchos de los parámetros que definen la oralidad conceptual se dan también en el discurso publicitario, donde no solo el producto sino sobre todo el consumidor y su universo ocupan un lugar destacado. Por ello, uno de los principales objetivos de los textos publicitarios es el acercamiento al destinatario (Hernández Toribio 2006: 71 y ss.) a través de un grupo heterogéneo de estrategias y recursos lingüísticos que fomentan la cercanía comunicativa.

En los medios tradicionales, se relacionan con la oralidad los recursos de integración del receptor (Janoschka 2004: 132 y ss.), como los vocativos (Hernández Toribio 2008: 243-244), los imperativos (Escribano 2018: 117), los enunciados interrogativos (Méndez 2000: 21) o la deixis de segunda persona y las expresiones de referencia personal al público objetivo (Hernández Toribio 2008: 238 o Serrano y Hernández Toribio 2015). Otra forma de promover el acercamiento al destinatario consiste en emplear el registro coloquial, tanto en la apelación directa al consumidor como en los 
«módulos conversacionales» (Hernández Toribio 2006) representados por los personajes de los mensajes publicitarios. Por último, las estrategias emocionales y de realce (Robles 2004; Janoschka 2004: 146 y ss.) también ocupan un lugar destacado, tanto en su vertiente expresiva relacionada con el producto, marca o servicio como en su vertiente afectiva de relación con el consumidor, manifestada, por ejemplo, en el humor, que tiene también en la publicidad una función destacada (Gulas y Weinberger 2006; Dynel 2020; Pano y Mancera 2016, entre otros).

El principal condicionante que diferencia a la publicidad en los medios tradicionales de la comunicación corporativa en las redes sociales es que la primera consiste en una publicidad de tipo intrusivo o no demandada, frente a la segunda, que ha de aportar un valor añadido para que el usuario se acerque a la marca. Teniendo esto en cuenta, los mensajes de Twitter de las cuentas corporativas se clasifican en dos tipos: los que persiguen un fin promocional similar al de los mensajes de la publicidad tradicional y los que persiguen aportar un valor añadido, normalmente, una experiencia fundamentada en el entretenimiento. Dicho de otro modo, los tuits pueden inclinarse bien hacia la presentación de mensajes promocionales o bien hacia el inicio de una conversación (Schröder 2017: 125):

Los tuits promocionales son típicamente cortos, fáciles de memorizar, recogen un mensaje promocional clave o incluyen imperativos, invitando, de ese modo, a que los usuarios hagan clic en un enlace que lleva a la web de la compañía. Los tuits que inician las discusiones, por otro lado, presentan los rasgos de la oralidad conceptual (íb. [traducción del autor]).

Según los estudios previos sobre la comunicación de Netflix España en Twitter (Fernández-Gómez y Martin-Quevedo 2018a y 2018b), la plataforma de contenidos audiovisuales trata de aportar un valor añadido a partir de una «estrategia de engagement», que persigue la interacción e implicación del usuario en su relación con la marca, mediante el empleo del lenguaje propio de la red y los recursos visuales.

\subsection{Imagen y comunicación multimodal}

El discurso digital y el publicitario se caracterizan por combinar diferentes códigos semióticos para alcanzar un propósito comunicativo común a través de la construcción de «textos coherentes multimodales» (Bateman 2014b). Entre estos códigos semióticos destacan el modo verbal y la imagen, cuyos «potenciales modales» (Kress 2010) interactúan para la construcción de significados que superan las aportaciones individuales de cada modo. Una particularidad del potencial semiótico de la imagen es su per- 
cepción inmediata y su adaptación a la comunicación de emociones (Müller y Kappas 2010, entre otros).

En cuanto a la interacción entre los dos modos, en el discurso digital la imagen suele mostrarse de dos maneras principales respecto al texto $(\mathrm{Du}-$ que 2020a): por un lado, puede escenificar una situación de enunciación simulada, encarnando al locutor y/o alocutario (Ducrot 1986) y, por otro lado, puede relacionarse con el contenido proposicional del mensaje verbal, manteniendo con este relaciones de correferencialidad intermodal (Royce 2007) que, con más trabajo inferencial, pueden tornar en las relaciones de analogía u oposición que caracterizan, por ejemplo, las interpretaciones irónicas y las metáforas multimodales (Forceville 2017 o Pérez Sobrino 2017). Una forma de estudiar de manera sistemática la integración entre texto e imagen consiste en trasladar al discurso multimodal los análisis de relaciones de discurso que describen la estructura y coherencia textual (Bateman 2014a; Garrido 2017; Molina et al. 2018; Taboada y Habel 2013), de modo que, al igual que en los textos monomodales, tanto si la imagen representa la situación de enunciación como si se relaciona con el contenido proposicional del texto, las relaciones intermodales se clasifican en tres familias: ampliación, semejanza o causa (Duque 2020a, 2020b y 2016).

La imagen por sí sola o en interacción con el modo verbal contribuye a la expresión de la cercanía y distancia comunicativa de diferentes maneras. El contenido ideacional de la imagen -los participantes y procesos representados (Kress y Van Leuween 2001: 45 y ss.)- puede indicar visualmente alguno de los parámetros que definen el continuo oralidad-escritura, como, por ejemplo, la cotidianidad o la implicación emocional. Igualmente, las propiedades estilísticas también suelen ser relevantes para enmarcar la interpretación interpersonal del texto (Detenberg y Lang 2010 o Wang y Peracchio 2007), comunicando diferentes grados de distancia o cercanía.

Los estudios previos sobre la comunicación de Netflix en Twitter España (Fernández-Gómez y Martín-Quevedo 2018b) destacan que los recursos visuales favorecen la interacción e implicación del usuario, siendo las imágenes el «elemento complementario» que más comentarios promueve, frente a otros como los emoticonos, enlaces o hashtags.

\section{Metodología}

El artículo propone un análisis de corpus de la cuenta de Twitter de la plataforma de vídeos bajo demanda Netflix, @NetflixES. El corpus está constituido por los 74 mensajes difundidos a través de dicha cuenta durante la primera quincena del mes de mayo de 2020. Incluye tanto los mensajes 
de creación propia como los retuiteados y descarta un análisis detallado de los tuits de respuesta de la comunidad de usuarios.

Tras un análisis exploratorio y teniendo en cuenta los fenómenos destacados en el apartado anterior, se decidió anotar y cuantificar las variables que detallamos a continuación. En cualquier caso, debe subrayarse que el foco del análisis es de tipo cualitativo y que los resultados cuantitativos (presentados en la Tabla 1) deben interpretarse con cautela, dado el tamaño limitado de la muestra. Por un lado, se anotaron un conjunto de variables que afectan a la configuración global del mensaje: finalidad del tuit (promocional o no promocional); tipo de tuit (contenido propio o retuit); imagen (presencia o ausencia); relación imagen-texto (ampliación, semejanza o causa); y número de respuestas al tuit. Por otro lado, se consideraron las siguientes variables relacionadas con los rasgos locales de la oralidad en las redes: uso de la primera y segunda persona, enunciados interrogativos y exclamativos, imperativos, vocativos, mayúsculas enfáticas o uso de emoticonos. Finalmente, teniendo en cuenta el análisis exploratorio previo, consideramos relevante anotar otros dos fenómenos que parecían recurrentes: tuits con formato de meme y tuits con referencia a asuntos de actualidad. La Tabla 1 recoge el número y porcentaje de tuits que presentan las princi-

\section{TABLA 1. Frecuencias y porcentajes de aparición de las principales variables anotadas}

\begin{tabular}{l|lrr}
\multicolumn{2}{c}{} & Frecuencia & \multicolumn{1}{c}{$\%$} \\
\hline \multirow{4}{*}{$\begin{array}{l}\text { Variables externas } \\
\text { o globales }\end{array}$} & Finalidad promocional & 51 & $(68,9 \%)$ \\
& Contenido propio & 50 & $(67,6 \%)$ \\
& Presencia de imagen & 58 & $(78,3 \%)$ \\
& Formato meme & 17 & $(23 \%)$ \\
& Anclaje en asuntos de actualidad & 10 & $(13,5 \%)$ \\
\hline \multirow{5}{*}{$\begin{array}{l}\text { Variables internas } \\
\text { o locales }\end{array}$} & Interrogaciones & 17 & $(23 \%)$ \\
& Exclamaciones & 4 & $(5,4 \%)$ \\
& Imperativos & 3 & $(4 \%)$ \\
& 2. persona ${ }^{a}$ persona & 42 & $(56,8 \%)$ \\
& Vocativos & 22 & $(29,7 \%)$ \\
& Mayúsculas enfáticas & 1 & $(1,4 \%)$ \\
& Emoticonos & 11 & $(14,8 \%)$ \\
\hline
\end{tabular}


pales variables globales y locales previamente descritas. El próximo apartado, que interpreta los datos en el marco de un análisis cualitativo, ejemplifica la anotación de dichas variables.

\section{ANÁLISIS Y DISCUSIÓN}

La oralidad conceptual se manifiesta ostensiblemente en nuestro corpus, tanto en rasgos léxicos y morfosintácticos como en las estrategias y efectos discursivos que asociamos con la inmediatez comunicativa, dando como resultado una comunicación muy cercana, entusiasta y humorística, donde la imagen desempeña un papel destacado. Por tanto, las diferentes variables situacionales que distinguen a las comunicaciones horizontales de las verticales no se reflejan de manera notoria en la variación interna del discurso. Es decir, la lengua utilizada en las comunicaciones profesionales, al menos en nuestro corpus, está muy influida por las convenciones orales del uso horizontal mayoritario que se da a las redes. Como señala Landert (2017: 46), parece ser que los comunicadores profesionales se han ajustado a un «estilo implicado» que es «la norma en estas plataformas». Este estilo, así como la explotación del humor (Hernández Toribio y Vigara Tauste 2011) se relaciona con las generaciones jóvenes, que son el principal grupo de comunicación digital (Overbeck 2017: 180) y que parecen definir las convenciones de las prácticas discursivas en las redes sociales.

El estilo oralizado, implicado e interactivo se manifiesta en todo tipo de mensajes, tanto en los que no presentan un objetivo promocional concreto (31\%), como el ejemplo 1, como en los claramente promocionales $(69 \%)$, como el ejemplo 2, donde advertimos abundantes rasgos orales: el enunciado interrogativo, el pronombre de primera persona, el futuro perifrástico, el se aspectual o los acortamientos léxicos coloquiales. En nuestro corpus, por tanto, no se mantiene la distinción de estilos entre los dos tipos de mensajes (Schröder 2017), que reserva las características de la oralidad para los tuits no promocionales. Por el contrario y dado que los mensajes promocionales suelen generar rechazo en los usuarios (Fernández-Gómez y Martin-Quevedo 2018a: 1293), una estrategia muy habitual para hacerlos más atractivos y fomentar la implicación del usuario consiste en presentar la promoción con un enunciado de estilo interactivo, propio de la comunicación personal cara a cara.

Los rasgos orales que permean nuestro corpus se explican a partir de tres parámetros del continuo oralidad-escritura que han sido destacados para el discurso de las redes sociales por diferentes autores: la dialoguicidad (Pano y Mancera 2014), la implicación emocional y valorativa (Landert 2017) y una familiaridad aparente o ambiente de afiliación (Martin 2010; 
Figura 1. Ejemplos 1 y 2
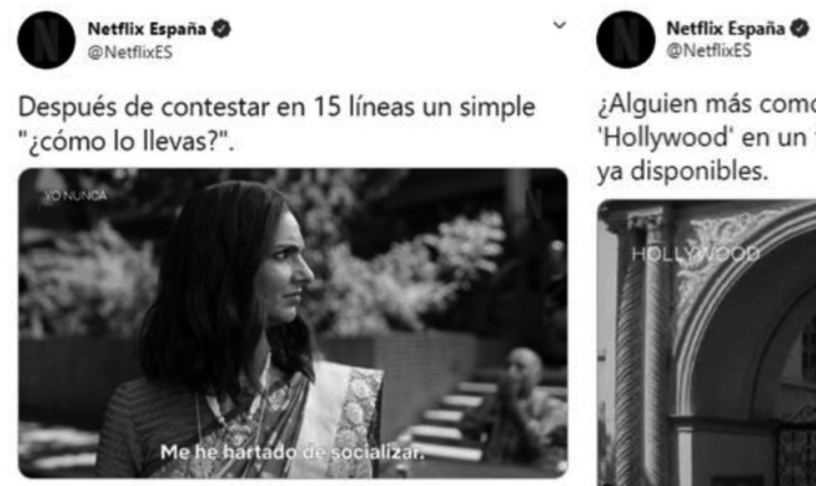

¿Alguien más como nosotros que se va a ver 'Hollywood' en un finde? Todos los episodios ya disponibles.

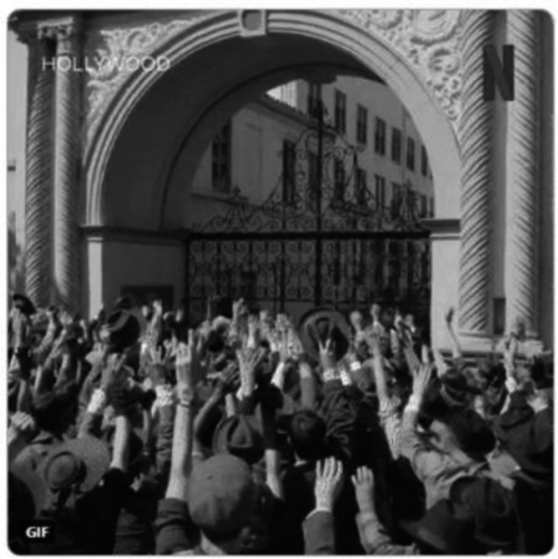

Knight 2010; Zappavigna 2012, 2017) creado por los intereses comunes y por el contexto cognitivo compartido por la comunidad de usuarios. La imagen también participa de la expresión de estos tres parámetros, que se presentan extremadamente intrincados, en tanto que la dialoguicidad o interacción es a su vez el principal modo de generar implicación emocional y de crear comunidad.

\subsection{Dialoguicidad e interacción}

La publicidad tradicional pretende generar la impresión de comunicación interpersonal, mientras que, en la comunicación corporativa en las redes sociales, esta impresión o simulación se transforma, con frecuencia, en un diálogo real con el consumidor, gracias a la diferente "potencialidad comunicativa» de los medios digitales (Hutchby 2001 o Virtanen 2017).

A pesar de que, como ilustra el ejemplo 2, los rasgos oralizantes relacionados con la dialoguicidad se incluyen también en los mensajes promocionales para hacerlos más atractivos, la efectividad de esta estrategia sigue siendo limitada, como demuestra que este tipo de mensajes genera menos diálogo entre los usuarios: en el cuartil con menos respuestas, el $89 \%$ de los tuits son promocionales, frente al $58 \%$ en el cuartil más interactivo. 
Dicho de otro modo, como era previsible y pese a los esfuerzos por dotar a los mensajes promocionales de la apariencia de dialoguicidad, los no promocionales obtienen mejores índices de interacción. Asimismo, en contra de lo esperado (Fernández-Gómez y Martín-Quevedo 2018b), los tuits sin imagen, como el ejemplo 3 (el más respondido de nuestro corpus), generan más diálogo, quizás porque normalmente los mensajes sin imagen no son promocionales.

(3) Netflix España (@NetflixES). Dinos el nombre de tu grupo de amigas en WhatsApp y te recomendamos un título.

Las características de la dialoguicidad aparecen en nuestro corpus en tres formatos diferentes. En primer lugar, como dialoguicidad directa que busca una respuesta genuina del usuario (ej. 3); en segundo lugar, como dialoguicidad retórica, que no fuerza la reacción del usuario (ej. 2); y, por último, como dialoguicidad fingida, en pequeños «módulos conversacionales» (Hernández Toribio 2006) que reproducen en discurso directo las palabras de un personaje representado en la imagen (ej. 1). En raras ocasiones, se combinan estos tipos de dialoguicidad, como en el ejemplo 4, el segundo que genera más interacción en nuestro corpus, el cual une la apelación auténtica al usuario con el discurso directo sobreimpreso en la imagen.

FigURA 2. Ejemplos 4 y 5

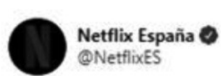

¿Qué actor o actriz verías siempre sin importar lo buena o mala que sea la serie o peli?

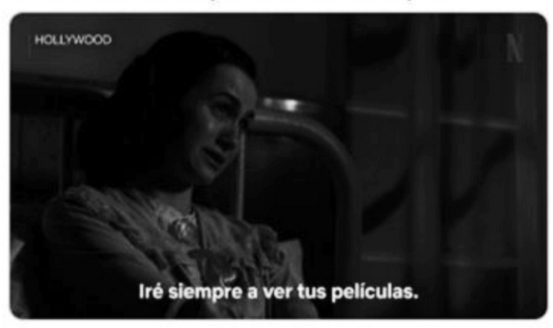

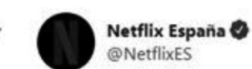

Habíamos quedado hoy, ¿no? Todos los episodios de \#ValeriaNetflix ya están disponibles.

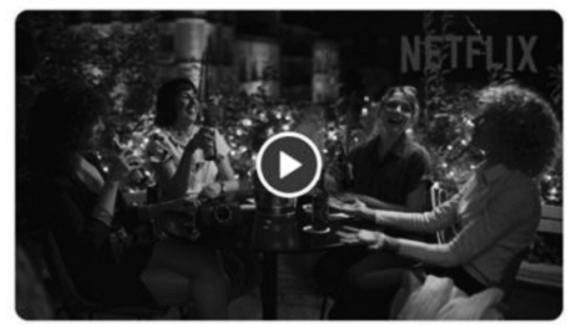

En cuanto a los rasgos discursivos relacionados con la dialoguicidad, destacan el uso de la primera persona presente en el $57 \%$ de los mensajes; de la segunda persona $(30 \%)$ y los enunciados interrogativos $(23 \%)$. Por el contrario, frente a lo indicado en la bibliografía, los vocativos y los imperativos no presentan frecuencias de aparición altas. Los vocativos solo son utilizados en un tuit de nuestro corpus, en el marco de un módulo conver- 
sacional, y los imperativos, como en el ejemplo 3, están presentes en el $4 \%$ de los tuits analizados. Se advierten, además, otros rasgos asociados a la dialoguicidad que no hemos anotado sistemáticamente, como el marcador de contacto ilustrado en el mensaje promocional de 5 (Figura 2). Como ilustra ese mismo ejemplo, el empleo de la primera persona del plural se relaciona con la dialoguicidad, pero también, con el parámetro de la familiaridad, especialmente cuando su referencia incluye a la audiencia (compárese con el ejemplo 2).

En general, como se advierte en los ejemplos seleccionados, la dialoguicidad está al servicio del fomento de la familiaridad, al tratar temas como los gustos personales y las relaciones interpersonales. Asimismo, también fomenta la implicación emocional, en tanto que, como ocurre en la publicidad tradicional, los deícticos de persona asociados a la dialoguicidad se utilizan para «transmitir la sensación de tener en cuenta constantemente a su interlocutor, como por otra parte, sucede habitualmente a la conversación cotidiana» (Hernández Toribio 2008: 222). Esta sensación se torna en real en la publicidad en las redes sociales, al solicitar y valorar la opinión del usuario, que se siente no solo partícipe de una comunidad, sino también escuchado por la marca, como ilustran los ejemplos 3 y 4.

\subsection{Implicación emocional}

La dialoguicidad en el discurso publicitario de Netflix está cargada emocionalmente de dos maneras principales. Por un lado, se trata de una interacción con un estilo enfático y entusiasta y, por otro, persigue la asociación de la marca a la diversión y emociones positivas mediante el uso generalizado del humor, que es la principal estrategia de implicación emocional presente en nuestro corpus.

Uno de los formatos que consigue los mencionados efectos humorísticos son los memes creados a partir de fotogramas recontextualizados de las series de la plataforma, como el ejemplo 1. Este tipo de mensajes de creación propia constituye el $23 \%$ de los tuits de nuestro corpus y presenta la clase de dialoguicidad fingida mencionada en el apartado anterior. En general, como se advierte en los ejemplos previos, tanto las imágenes de los memes como las del resto de tuits, representan frecuentemente procesos psicológicos o de comportamiento, mediante una gestualidad enfática y exagerada que es una de las principales formas de comunicación de las emociones en nuestro corpus.

La implicación emocional también se manifiesta mediante un discurso valorativo y enfático más tradicional, que en la publicidad suele perseguir el realce de las cualidades del producto (Robles 2004). Estas valoraciones se realizan principalmente a través de mensajes retuiteados, que califican y 
recomiendan explícitamente los contenidos de la plataforma, como vemos en los ejemplos 6, 7 y 8 (genial, recomendable, adictiva, gran descubrimiento...). Cabe destacar que en la recontextualización que supone la operación de retuit, el mensaje original se transforma en un tipo de publicidad testimonial que aprovecha la autenticidad del mensaje y, por tanto, la veracidad que se le presupone a la valoración positiva del usuario. Los mensajes propios de la plataforma, en cambio, tratan de evitar la calificación directa de sus propios contenidos, ya que esta se asocia a los mensajes promocionales que generan cierto rechazo de los usuarios ${ }^{2}$.

FigURA 3. Ejemplo 6

v. Netflix España retwitteó

Diego Cortezón

@cortebing

Pero que genial es la serie \#Deadtome2 de @NetflixES, es que si no la has visto estás tardando.

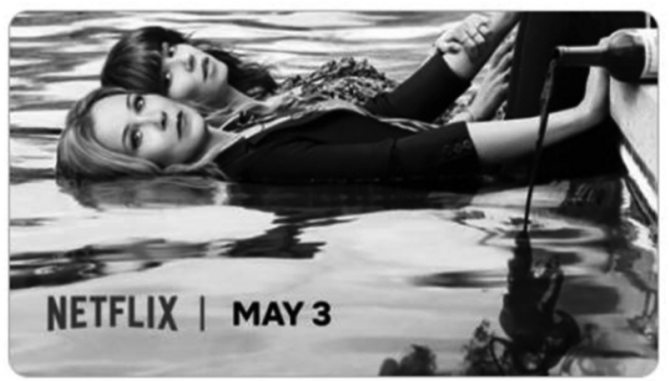

(7) Juka (@jukaPerci). Madre mía me quedo loco con \#Hollywood de $@$ NetflixES al ver todos los salseos y tejemanejes de la época dorada del cine. Muy recomendable.

(8) Emilio Carrión (@emilio_carri). Me lo he pasado pipa viendo la tres temporadas de \#Fauda en Serie muy adictiva sobre el conflicto en orientemedio ;Gran descubrimiento!

2 Asimismo, aunque las etiquetas o hashtags (\#) presentan la ventaja de fomentar la difusión del mensaje, también parecen estar fuertemente asociadas a los fines promocionales. Quizás por ello, frente a lo sugerido por la literatura (Fernandez-Gómez y Martín-Quevedo 2018a y 2018b, entre otros), los tuits de nuestro corpus suelen evitar esta funcionalidad, que solo está presente en el $14 \%$ de los mensajes con contenido propio y que destaca, en cambio, en los mensajes retuiteados. 
Como se observa en los ejemplos, los retuits siguen un estilo oralizado muy enfático, característico de una alta implicación emocional: nótese el pero enfático inicial, el operador informativo es que o la segunda persona en 6; la expresión interjectiva madre mía, la primera persona o el léxico coloquial y juvenil (quedarse loco o salseo) en 7; y la primera persona, el léxico coloquial (pasárselo pipa) y el enunciado exclamativo en 8. Los mensajes con contenidos propios también despliegan un estilo enfático; sin embargo, como se ha indicado, no lo hacen para recomendar de manera directa los contenidos de la plataforma, sino para expresar una emoción exagerada por un estreno inminente, explotando la pasión contagiosa característica del fenómeno fan, como ilustra el ejemplo 9.

La implicación emocional y comunicación enfática en 9 se manifiesta en el propio contenido del mensaje, en su selección léxica, en la imagen y en otros recursos, como las mayúsculas enfáticas o el enunciado exclamativo, si bien en nuestro corpus estos dos últimos «marcadores de intensidad» no están tan generalizados como sugiere la literatura (Tannen 2013): el $15 \%$ de los mensajes emplea mayúsculas enfáticas (limitadas a una única palabra), solo el $5 \%$ contiene signos de exclamación, el $11 \%$ presenta emoticonos y las reduplicaciones de vocales o signos ortográficos son muy inusuales. Como nota Tannen (íb.), en determinados contextos digitales estos marcadores de intensidad pueden ser tan habituales que se configuran como los rasgos no marcados, de modo que resultan necesarios para evitar la impresión de apatía o negatividad (íb. p. 100); sin embargo, en

Figura 4. Ejemplo 9

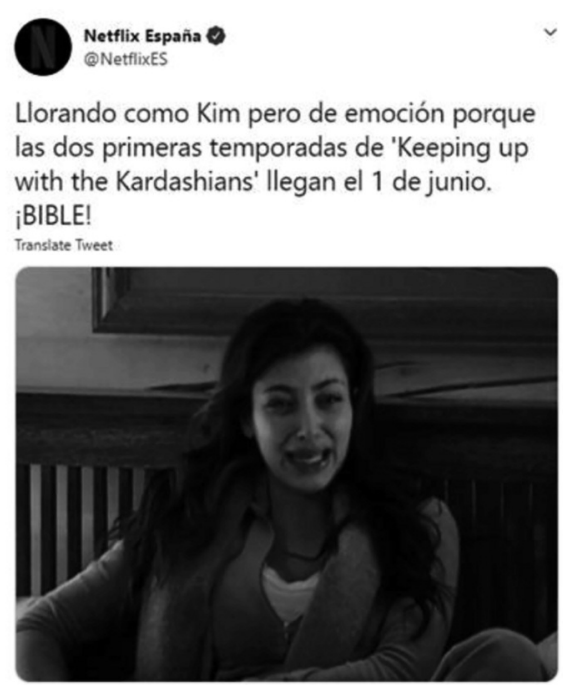


nuestro corpus esta comunicación enfática no se fundamenta en dichos marcadores, que no son tan frecuentes, sino, sobre todo, en la selección léxica, en la imagen y en el uso del humor.

\subsection{Familiaridad}

Dado que los usuarios de Twitter no se conocen y sus comunicaciones son de carácter público, puede resultar paradójico destacar el grado de familiaridad como otro de los parámetros que condicionan la comunicación publicitaria en este medio. Por ello, es necesario subrayar que se trata de una familiaridad aparente y diferente a la referida en Koch y Oesterreicher (2007), ya que no es «previa al plano material discursivo» (Cortés 2012: 5), sino que se origina en el propio discurso. Esta familiaridad fomenta «un tipo particular de pertenencia» habitual en Twitter (Zappavigna 2017: 216), por la que los usuarios se sumergen en un «ambiente de afiliación» (Martin 2010; Knight 2010; Zappavigna 2012) fundado en conocimientos compartidos e intereses y gustos comunes. Dicho ambiente de afiliación, además, genera un sentido de comunidad, que puede conducir a un mayor grado de identificación (y, por tanto, lealtad) con productos, compañías o partidos políticos (Landert 2017: 37).

Como se ha indicado, la familiaridad en nuestro corpus se manifiesta de una manera fuertemente intrincada a la implicación emocional y a la dialoguicidad. De hecho, estos dos condicionantes son imprescindibles para lograr el ambiente de confianza aparente entre los interlocutores. Respecto a la implicación emocional, cabe destacar el uso del humor que, como indica Knight (2010), es un indicador explícito de la creación de afiliación y de la construcción de identidades de grupo (Partington 2006), al crear vínculos positivos entre los usuarios que se ríen juntos y que consideran graciosas las mismas bromas.

En cuanto a la relación entre dialoguicidad y familiaridad, como muestran los ejemplos 5 y 10 , el uso de la primera persona del plural, cuando incluye al interlocutor, fomenta el sentimiento de pertenencia a una comunidad de usuarios que comparte gustos e intereses. No en vano, la primera persona del plural «destaca la implicación personal y es característica de géneros y contextos donde el compartir es un valor pragmático destacado» (Aijón Oliva 2020: 4). Asimismo, este último ejemplo (10) y también 3 y 4 ilustran el tipo de dialoguicidad directa que se relaciona con la creación del ambiente de afiliación, ya que en ellos se utiliza el diálogo para solicitar la opinión del usuario, que, de este modo, se convierte en un partícipe activo de una comunidad en la que se construyen los significados de manera negociada. 
(10) Netflix España (@NetflixES). Hagamos una lista de personajes que deberían haberse quedado en casa, empezamos nosotros:

-Will Byers (Stranger Things)

-Arturito (LCDP)

-Candace (You)

La familiaridad en nuestro corpus se manifiesta también en las situaciones representadas y en los temas tratados, entre los que sobresalen de manera muy destacada los del ámbito de las relaciones interpersonales y la amistad. En este sentido, una estrategia repetida consiste en exponer una experiencia enmarcada en las relaciones interpersonales con la que los usuarios se sienten identificados. En nuestro corpus, estas situaciones se realizan en forma de meme con imagen integrada, como el ejemplo $1 \mathrm{u} 11$, o de forma monomodal, como en los ejemplos 12, 13 y 14.

FIGURA 5. Ejemplo 11

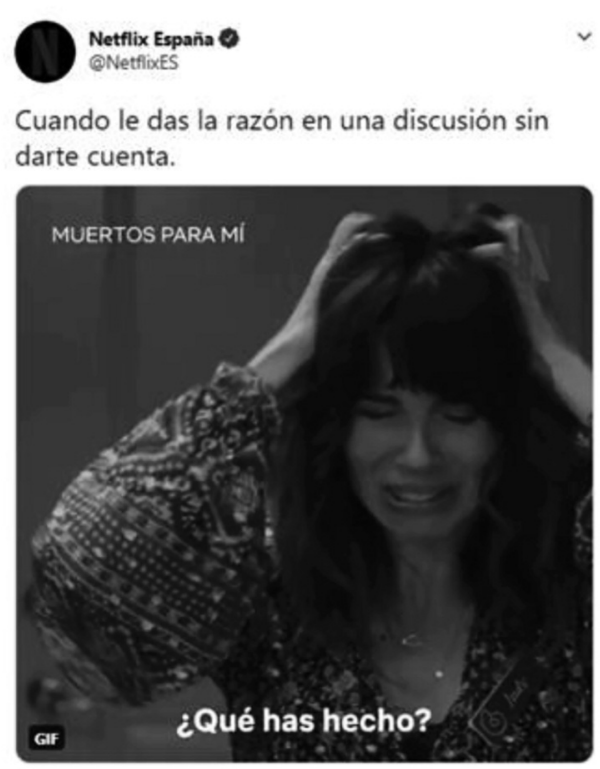

(12) Netflix España (@NetflixES). Corre el rumor de que las conversaciones en el grupo familiar empiezan todas con una de estas dos preguntas:

- ¿Cómo estás?

$-¿$ Me recomiendas algo que ver?

(13) Netflix España (@NetflixES). Ver una serie con alguien que mira todo el rato el móvil no se disfruta igual. Alguien tenía que decirlo. 
(14) Netflix España (@NetflixES). Compartir frases de series como indirecta es el nuevo "pongo esta canción en el nick y a ver si lo pilla».

Por último, otra estrategia destacada de fomento de la familiaridad consiste en «explotar el conocimiento compartido» (Mancera 2020) mediante los temas de actualidad que unen a los usuarios en un contexto de vivencias comunes. Esta estrategia, presente en el $14 \%$ de los tuits de nuestro corpus, se manifiesta en los textos en forma de implicaturas conversacionales gobernadas por el conocimiento sobre la actualidad, y demuestra la conocida «capacidad de Netflix para aprovechar eventos sociales o de actualidad para promocionar sus propios contenidos» (Fernández-Gómez y MartínQuevedo 2018a: 1300).

La actualidad del momento de recolección de nuestro corpus está marcada por el confinamiento domiciliario provocado por la crisis sanitaria de la COVID 19. Como muestran los ejemplos 15, 16 y 17, esta situación es estratégicamente utilizada por la plataforma para generar complicidad con sus seguidores, que soportan circunstancias parecidas y comparten una experiencia común. La complicidad también se crea por la satisfacción que experimenta el usuario al resolver la implicatura, que, por inesperada, provoca el efecto humorístico.

Cabe destacar que estos tuits, al igual que todos los que conforman nuestro corpus, integran en el mensaje, aunque sea de manera circunstancial, algún contenido de la plataforma o, al menos, el hábito de consumir series

(15) Netflix España (@NetflixES). ¿Cuándo va a acabar este capítulo de Black Mirror?

Figura 6. Ejemplos 16 y 17

Netflix Esparĭa

@NetflixES

El regreso más esperado.

Translate Tweet

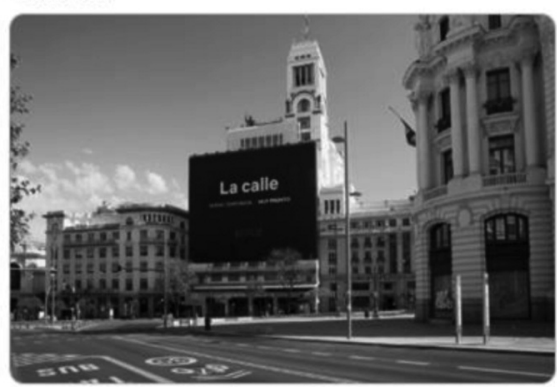

Netflix España

@Netfliox

En Moordale no iban nada desencaminados. \#SexEducation

Transiate Tweet

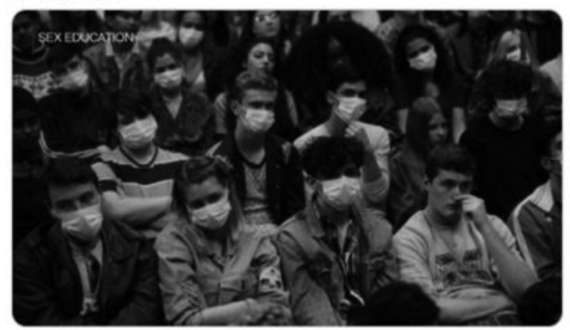


de televisión. Así, 15 se refiere a la pandemia mediante la serie distópica Black Mirror; en 16, el humor basado en la intertextualidad (Pano y Mancera 2016: 48) presenta la metáfora por la que salir a la calle tras el confinamiento se concibe como el estreno de una temporada de una serie de éxito; y 17 recontextualiza la imagen de la serie británica Sex Education para hacerla significativa en el contexto de la crisis sanitaria.

\subsection{Imagen}

El $78 \%$ de los tuits de la cuenta de Twitter de Netflix España son textos multimodales en los que el modo verbal y visual interactúan de diferentes maneras para la construcción de un significado unitario. El $22 \%$ de los mensajes del corpus contiene solo texto y ningún tuit consiste únicamente en una imagen, ya sea estática o vídeo. De este modo, los resultados de nuestro análisis apuntan a que los tuits no marcados en la comunicación publicitaria en Twitter son textos multimodales en los que existe una «predominancia constitutiva» (Parodi y Julio 2017) del modo verbal.

Pueden distinguirse dos tipos de imágenes por su formato y por su comportamiento discursivo. Los vídeos, que representan el $27 \%$ de los contenidos gráficos de nuestro corpus, amplían la información del texto escrito y están poco integrados con él. Las imágenes estáticas y las animadas de formato GIF suponen el $73 \%$ restante, presentan diferentes grados de integración con el texto y sus funciones discursivas son más variadas.

Los vídeos muestran una propensión muy alta de aparición en tuits promocionales. En la mayor parte de los casos, ofrecen un tráiler de algún contenido de la plataforma que amplía la información del texto si el usuario está interesado (véase, por ejemplo, 5), de modo que el nivel de integración entre el texto del tuit y el vídeo es bajo. Las imágenes estáticas y animadas en formato GIF desempeñan funciones discursivas más variadas que los vídeos y se combinan con el texto de diferentes maneras. Al igual que el vídeo, la imagen puede ampliar el contenido proposicional del texto de una manera poco integrada, como en el ejemplo 6 , o puede hacerlo de una forma más integrada como en los ejemplos 16-19. En el caso de los tuits de dialoguicidad fingida, la imagen suele representar la situación de enunciación, construyendo entonces relaciones de Proyección o Atribución con el texto (Duque 2020a), como en 1, 4 y 11. El resto de relaciones discursivas, como las de semejanza de los ejemplos 18 y 19 aparecen escasamente representadas.

La imagen también participa en la comunicación de la cercanía comunicativa que caracteriza a nuestro corpus. Presenta una función discreta en el fomento de la dialoguicidad y de la familiaridad; en cambio, desempeña 
Figura 7. Ejemplos 18 y 19
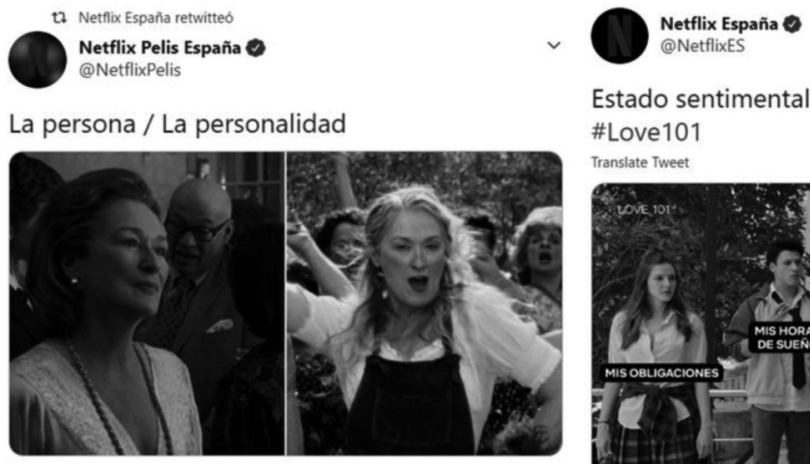

Estado sentimental: viendo una serie turca. \#Love101

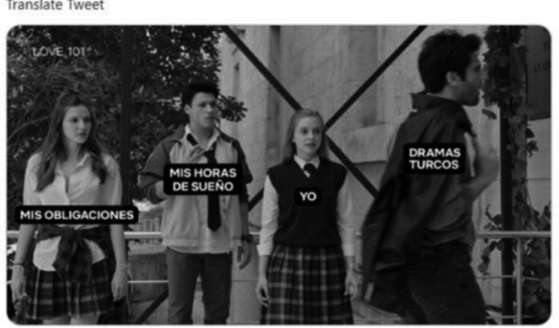

un papel muy destacado en la implicación emocional. En cuanto a la dialoguicidad, como se ha indicado, los tuits sin imagen suelen generar mucha interacción, como demuestra que el $50 \%$ de los mensajes sin imagen se sitúan en el cuartil más interactivo. Estos resultados apuntan a que, en un entorno donde la mayor parte de los mensajes contiene una imagen, los tuits monomodales llaman la atención en mayor medida y son percibidos como un intento de comunicación menos promocional y planificada y más auténtica y directa.

En cuanto a la implicación emocional, la imagen suele presentar a personajes de las series escenificando procesos relacionados con emociones intensas, mediante una gestualidad exagerada y frecuentemente en el marco de mensajes de dialoguicidad fingida. En general, la imagen en nuestro corpus manifiesta su especial adaptación a representar y suscitar emociones (Müller y Kappas 2010: 327), dado que percibimos las emociones en los demás principalmente a través de la visión (íb. 311). En el caso de los memes, como 1 u 11, la recontextualización de estas emociones se logra a través de los motivos triviales apuntados en el texto (Duque 2020a), que activan la oposición de marcos interpretativos en la que se fundamenta el resultado humorístico (Attardo 2010). Respecto a la familiaridad, además del papel fundamental que desempeña la imagen en la consecución de los efectos humorísticos que estrechan los lazos de la comunidad, la información que aporta la imagen también suele ser fundamental para la resolución de las implicaturas gobernadas por el conocimiento de actualidad, las cuales sitúan a los usuarios en un contexto vivencial común, como muestran los ejemplos 16 y 17.

Por último, en cuanto a las características formales de la imagen, estas aparecen editadas de manera profesional y mantienen una estética corpo- 
Figura 8. Ejemplo 20

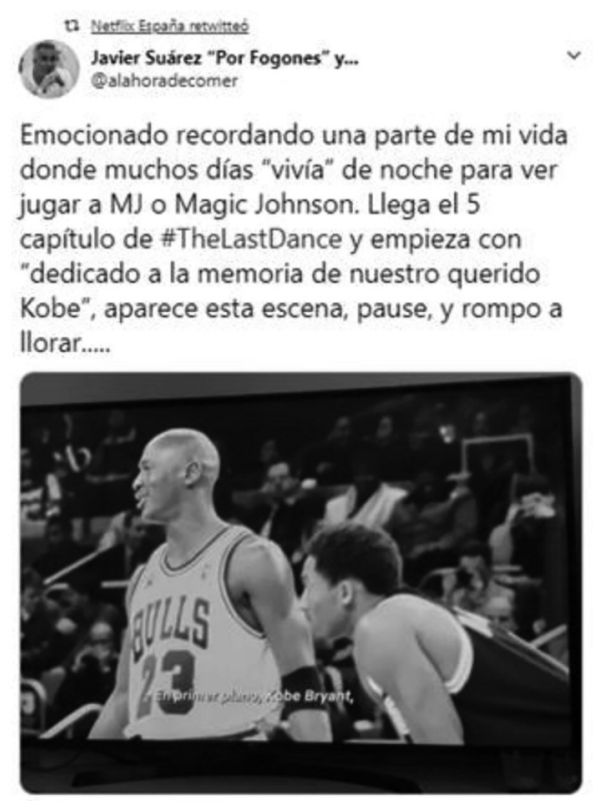

rativa, que las aleja de las prácticas de las comunicaciones horizontales de las redes sociales y, por tanto, en este sentido, no expresan cercanía comunicativa. La mayor parte de las imágenes de nuestro corpus son fotogramas de primeros planos de los contenidos de la plataforma, que suelen indicar en la esquina superior izquierda la serie de la que está tomada dicho fotograma y, en la esquina superior derecha, el logotipo de Netflix. Las imágenes con una apariencia menos cuidada solo aparecen en mensajes retuiteados, como en el del ejemplo 20, en el que la instantánea al televisor expresa una gran cercanía comunicativa y trabaja para la comunicación de la veracidad y autenticidad del mensaje, que es aprovechada por la plataforma en su retuit.

\section{Conclusiones}

Desde el punto de vista de la variación externa del discurso, la comunicación publicitaria en las redes sociales presenta unos condicionantes particulares que la diferencian de la comunicación horizontal en los medios digitales y de la comunicación publicitaria en otros soportes. Sin embargo, nuestro análisis de la cuenta de Twitter de la plataforma de contenido 
audiovisual Netflix refleja que, en lo que respecta a la variación interna, las diferencias con las comunicaciones horizontales no están tan marcadas, ya que el discurso publicitario en las redes sociales parece mimetizar los rasgos orales propios del estilo implicado de la comunicación entre amigos.

Sí se advierten, en cambio, diferencias respecto a la publicidad tradicional en la variación interna del discurso. Estas diferencias están provocadas por la potencialidad interactiva de las redes sociales y por el carácter no intrusivo de su publicidad. La potencialidad interactiva de los medios digitales se manifiesta en que el discurso publicitario propone en estos medios una dialoguicidad real con la comunidad de usuarios, a los que invita a construir significados de manera negociada. El carácter no intrusivo, por su parte, se manifiesta en el esfuerzo constante por aportar un valor añadido a la comunicación, en forma de experiencias entretenidas fundamentadas en el humor.

Las características de la oralidad conceptual se despliegan en nuestro corpus de manera muy notoria y generalizada, tanto en rasgos morfosintácticos como en las estrategias discursivas propias de la cercanía comunicativa. Estos rasgos de la oralidad se explican a partir de tres parámetros principales del continuo inmediatez-distancia comunicativa: la dialoguicidad, la implicación emocional y la familiaridad.

La dialoguicidad se refleja en nuestro corpus en la búsqueda activa de la participación de los usuarios para la construcción colaborativa de significados. Asimismo, los rasgos lingüísticos asociados a la dialoguicidad, como el uso de la segunda persona o los enunciados interrogativos, aparecen fuertemente representados en nuestro corpus. En cambio, no son frecuentes otros rasgos destacados en la bibliografía, como los vocativos y los imperativos.

La implicación emocional no se refleja de manera destacada en los indicadores de énfasis característicos del discurso digital, como el uso de mayúsculas enfáticas, la reduplicación de caracteres, los enunciados exclamativos o los emoticonos. Nuestro corpus presenta, no obstante, un indudable estilo enfático e implicado emocionalmente, que es construido a partir de la selección léxica, de la imagen y del uso generalizado del humor.

El humor es también un indicador del ambiente de afiliación asociado al parámetro de la familiaridad. Otras estrategias que fomentan la familiaridad en nuestro corpus son las implicaturas conversacionales gobernadas por asuntos de actualidad, que presuponen un marco vivencial compartido; la selección temática, fuertemente enmarcada en el ámbito de las relaciones interpersonales; y el frecuente uso de la primera persona del plural, que afianza el sentimiento de familiaridad, afiliación y pertenencia.

Por último, en cuanto a la imagen, su nivel de integración con el texto es reducido en el caso de los vídeos. El resto de formatos se integran en mayor medida con el texto, ya sea ampliando su información proposicional o, 
sobre todo, representando la situación de enunciación simulada en la que el texto tiene lugar. Son inusuales las relaciones intermodales más informativas, como las de la familia de semejanza.

Respecto a la contribución del modo visual a la oralidad conceptual, la imagen no fomenta la dialoguicidad directa con los usuarios, que perciben los mensajes verbales monomodales como una interacción más auténtica y menos planificada. En cambio, la imagen sí desempeña un papel destacado en la expresión de la dialoguicidad fingida, encarnando, como se ha indicado, situaciones de enunciación en la que la gestualidad exagerada de los participantes es protagonista. En este sentido, las principales aportaciones de la imagen son la representación de una emotividad enfática y la participación en los efectos humorísticos y en las implicaturas conversacionales que fomentan la familiaridad y, por tanto, ayudan a crear comunidad. 


\section{BIBLIOGRAFÍA}

ATtARdo, Salvatore (2010 [2001]): Humorous Texts: A Semantic and Pragmatic Analysis, Berlín: Walter de Gruyter.

AJjón, Miguel (2020): «It Can be Us or You. The Desubjectification of Viewpoint through Person Choice in Spanish Oral and Written Media Discourse», Journal of Pragmatics 163, 4-17.

BATEMAN, John (2014a): Text and Image: A Critical Introduction to the Visual/Verbal Divide, Londres: Routledge.

- (2014b): «Multimodal Coherence Research and its Applications». En Helmut Gruber y Gisela Redeker (eds.), The Pragmatics of Discourse Coherence, Ámsterdam: John Benjamins, 145-177.

Biber, Douglas, Mark DaVIES, James Jones y Nicole Tracr-Ventura (2006): «Spoken and Written Register Variation in Spanish», Corpora 1/1, 1-37.

Bös, Birte y Sonja Kleinke (2017): «Publicness and Privateness». En Christian Hoffmann y Wolfram Bublitz (eds.), Pragmatics of Social Media, Berlín: de Gruyter, 83-122.

BrIZ, Antonio (2010): «Lo coloquial y lo formal, el eje de la variedad lingüística». En Rosa M. Castañer y Vicente Lagüéns (coords.), De moneda nunca usada: Estudios dedicados a José María Enguita Utrilla, Zaragoza: Instituto Fernando el Católico, 125-133.

Cantamutto, Lucía y Cristina Vela Delfa (2016): «El discurso digital como objeto de estudio: de la descripción de interfaces a la definición de propiedades». Aposta. Revista de Ciencias Sociales 69, 296-323.

CONRAD, Susan y Douglas BIBER (2013 [2001]): Variation in English: Multi-Dimensional Studies, Londres: Routledge.

CORTÉs, Luis (2012): «Los límites del discurso: condicionantes y realizaciones», Círculo de Lingüistica Aplicada a la Comunicación 51, 3-50.

- y Matilde Camacho (2003): ¿Qué es el análisis del discurso? Barcelona: Octaedro.

Chiaro, Delia (2017): The Language of Jokes in the Digital Age, Londres: Routledge.

ESCRIBANO, Asunción (2018): La redacción publicitaria, Madrid: Síntesis.

Detenber, Benjamin y Annie LANG (2011): «The Influence of Form and Presentation Attributes of Media on Emotion». En Katrin Dövelin, Christian von Scheve y Elly Konijn (eds.), The Routledge Handbook of Emotions and Mass Media, Londres: Routledge.

DuCROT, Oswald (1986): El decir y lo dicho: polifonía de la enunciación, Barcelona: Paidós.

DUQue, Eladio (2016): Las relaciones de discurso, Madrid: Arco/Libros.

- (2020a): «Relaciones entre texto e imagen en el discurso digital», Cuadernos AISPI 16/2, 143-162.

- (2020b): «Neuter Pronoun ello and Discourse Verbs in Spanish», Journal of Pragmatics 155, 273-285. 
DyNel, Marta (2020): «On Being Roasted, Toasted and Burned: (Meta) pragmatics of Wendy's Twitter Humour», Journal of Pragmatics 166, 1-14.

FERNÁNDEZ-Gómez, Erika y Juan MARTín-Quevedo (2018a): «La estrategia de $e n$ gagement de Netflix España en Twitter», El profesional de la información 27/6, $1292-1302$.

— y - (2018b): «Connecting with Audiences in New Markets: Netflix's Twitter Strategy in Spain», Journal of Media Business Studies, 15/2, 127-146.

ForCEVILLE, Charles (2017): «Visual and Multimodal Metaphor in Advertising: Cultural Perspectives», Styles of Communication 9/2, 26-41.

Gallardo-Paúls, Beatriz, Salvador Enguix y Joan OleaQue (2018): «Estilos de gestión de los perfiles políticos en Twitter: imagen y texto en las cuentas de los partidos en la campaña del 26J», Revista de Investigación Lingüistica 21, 15-51.

GARCía Aguiar, Livia (2019): «Mensajes condensados en 280 caracteres: Twitter». En Sara Robles y Antonio Moreno-Ortiz (eds.), Comunicación mediada por ordenador: la lengua, el discurso y la imagen, Madrid: Cátedra.

GARRIDO, Joaquín (2008): «Imagen y palabra en la construcción de discurso del texto publicitario", Español Actual 86, 81-103.

- (2017): «Segmentación del discurso e interacción», Círculo de Lingüística Aplicada a la Comunicación 71, 36-62.

GonzÁlez Ruiz, Ramón y Concepción MARTínez PASAMAR (2002): «La competencia lingüística». En M. Victoria Romero (coord.), Lengua española y comunicación, Barcelona: Ariel, 51-94.

Gulas, Charles y Marc Weinberger (2006): Humor in Advertising. A Comprehensive Analysis, Londres: M. E. Sharpe.

Helfrich, Uta (2018): «I Need Spain: New Ways of Representing the Tourist Experience». En Gudrun Held (ed.), Strategies of Adaptation in Tourist Communication, Leiden: Brill, 73-94.

Hernández Toribio, M. Isabel (2008): «La lengua de la publicidad: algunas estrategias al servicio de la persuasión emocional». En Antonio Arroyo (coord.), La lengua española en los medios de comunicación y en las nuevas tecnologías, Madrid: Laberinto.

- (2006): El poder de la palabra en la publicidad de radio, Barcelona: Octaedro.

- y Laura MARIotTINi (2020): «Actos de habla expresivos y emociones en entornos digitales: publicidad en Twitter». En Luis Bagué Quílez y Susana Rodríguez Rosique (eds.), Del tópico al eslogan: discurso, poesía y publicidad, Madrid: Visor, 53-65.

- y Ana M. Vigara (2011): «Los jóvenes en la publicidad: el estereotipo collage y el recurso al humor como estrategias pragmalingüísticas de persuasión emocional», Revista de estudios de juventud 93, 41-60.

Herring, S. (2007): «A Faceted Classification Scheme for Computer-Mediated Discourse»,Language@Internet 4/1.<https://www.languageatinternet.org/ articles $/ 2007 / 761>$.

Hutchby, Ian (2001): «Technologies, Texts and Affordances», Sociology 35/2, 441456.

JanoschKa, Anja (2004): Web Advertising. New Forms of Communication on the Internet, Ámsterdam: John Benjamins. 
Koch, Peter y Wulf Oesterreicher (2007 [1990]): Lengua hablada en la Romania: español, francés, italiano, Madrid: Gredos.

Kress, Gunther (2010): Multimodality: A Social Semiotic Approach to Contemporary Communication, Londres: Routledge.

- y Theo van LeEuwen (2001): Multimodal Discourse: The Modes and Media of Contemporary Communication, Londres: Arnold.

KNIGHT, Naomi (2010): «Wrinkling Complexity: Concepts of Identity and Affiliation in Humour». En Monika Bednarek y James Martin (eds.), New Discourse on Language: Functional Perspectives on Multimodality, Identity, and Affiliation, Londres: Continuum, 35-58.

LANDERT, Daniela (2017): «Participation as User Involvement». En Christian Hoffmann y Wolfram Bublitz (eds.), Pragmatics of Social Media, Berlín: de Gruyter Mouton, 31-59.

LóPez Serena, Araceli (2021): «Hablar y lo oral». En Óscar Loureda y Angela Schrott (coords.), Manual de lingüistica del hablar, Berlín: De Gruyter.

MANCERA, Ana (2020): «Saber y ganar seguidores en Twitter: estrategias publicitarias basadas en el conocimiento compartido». En Luis Bagué Quílez y Susana Rodríguez Rosique (eds.), Del tópico al eslogan: Discurso poesía y publicidad, Madrid: Visor Libros, 67-80.

- y Ana Pano (2013a): El español coloquial en las redes sociales, Madrid: Arco/ Libros.

— y - (2013b): «Nuevas dinámicas discursivas en la comunicación política en Twitter», Círculo de Lingüística Aplicada a la Comunicación 56, 53-80.

MARTIN, James (2010): «Semantic Variation: Modelling Realisation, Instantiation and Individuation in Social Semiosis». En Monika Bednarek y James Martin (eds.), New Discourse on Language: Functional Perspectives on Multimodality, Identity, and Affiliation, Londres: Continuum, 1-34.

MÉNDEZ, Elena (2000): «Los enunciados interrogativos en los textos publicitarios: un acercamiento pragmático», Questiones publicitarias 8, 9-25.

Molina, Marco, Liliana VÁsquez-Rocca y Giovanni PArodi (2018): «Relación palabra-gráfico en un género profesional de la economía», Círculo de Lingüistica Aplicada a la Comunicación 76, 153-179.

Müller, Marion y Arvid KaPPAS (2010): «Visual Emotions, Emotional Visuals: Emotions, Pathos Formulae, and their Relevance for Communication Research». En Katrin Doveling, Christian von Scheve y Elly Konijn (eds.), The Routledge Handbook of Emotions and Mass Media, Londres: Routledge, 324-345.

Overbeck, Anja (2017): «Orality and Literacy of Online Communication». En Kristina Bedijs y Christiane Maaß (eds.), Manual of Romance Languages in the Media, Berlín: De Gruyter.

PANO, Ana y Ana MANCERA (2014): «La 'conversación' en Twitter: las unidades discursivas y el uso de marcadores interactivos en los intercambios con parlamentarios españoles en esta red social», Estudios de lingüistica del español 35, 234-268.

- y - (2016): «Humor and Advertising in Twitter. An Approach from General Theory of Verbal Humor and Metapragmatics». En Leonor Ruiz Gurillo (ed.), Metapragmatics of Humor, Ámsterdam: John Benjamins. 
PARODI, Giovanni (2005): «Lingüística de corpus y análisis multidimensional: exploración de la variación en el corpus PUCV-2003», Revista Española de Lingüística 35/1, 45-76.

- y Cristóbal Julio (2017): «No solo existen palabras en los textos escritos: algunas teorías y modelos de comprensión de textos multimodales o multisemióticos», Investigaciones sobre Lectura 8, 27-48.

Partington, Alan (2006): The Linguistics of Laughter: A Corpus-assisted Study of Laughter-talk, Londres: Routledge.

PÉrez Sobrino, Paula (2017): Multimodal Metaphor and Metonymy in Advertising, Ámsterdam: John Benjamins.

RoBles, Sara (2004): Realce y apelación en el lenguaje de la publicidad, Madrid: Arco/ Libros.

Royce, Terry (2007): «Intersemiotic complementarity». En Terry Royce y Wendy Bowcher (eds.), New Directions in the Analysis of Multimodal Discourse, Londres: Lawrence Erlbaum, 63-109.

Serrano, M. José y M. Isabel Hernández Toribio (2015): «¿Porque tú lo vales o porque lo vales? Variación de la segunda persona tú en los mensajes publicitarios», Ibérica. Revista de la Asociación Europea de Lenguas para Fines Específicos 30, 105-128.

SCHÖDER, Tilman (2017): «Aspects of Advertising Language Online». En Kristina Bedijs y Christiane Maaß (eds.), Manual of Romance Languages in the Media, Berlín: De Gruyter, 111-129.

TABOADA, Maite y Christopher HaBel (2013): «Rhetorical Relations in Multimodal Documents», Discourse Studies 15/1, 65-89.

Tannen, Deborah (2013): «The Medium is the Metamessage: Conversational Style in New Media Interaction». En Deborah Tannen y Anna Marie Trester (eds.), Language and New Media, Washington: Georgetown University Press.

Yus, Francisco (2011): Cyberpragmatics. Internet-mediated Communication in Context, Ámsterdam: John Benjamins.

VÁsQuez, Camilla (2019): Language, Creativity and Humour Online, Londres: Routledge.

Virtanen, Tuija (2017): "Adaptability in New Media», Journal of Pragmatics 116, 21-26.

WANG, Kai-Yu y Laura Peracchio (2007): «Understanding the Stylistic Properties of Advertising Images». En Edward McQuarrie y Barbara Phillips (eds.), Go Figure! New Directions in Advertising Rhetoric, 205-226.

Zappavigna, Michele (2017): «Twitter». En Christian Hoffmann y Wolfram Bublitz (eds.), Pragmatics of Social Media, Berlín: de Gruyter, 201-224.

- (2012): Discourse of Twitter and Social Media: How We Use Language to Create Affiliation on the Web, Londres: Bloomsbury. 